\title{
La evolución de la novela artúrica francesa
}

\author{
Rosalba LENDO FUENTES \\ Universidad Nacional Autónoma de México
}

La palabra "roman", que en francés moderno se traduce como novela, significaba en francés antiguo lengua vulgar o románica. Durante la segunda mitad del siglo XII, la expresión "mettre en roman" (traducir a la lengua románica, es decir, al francés), comienza a figurar en los textos que adaptan libremente obras escritas en latín. "Mettre en roman" remite pues a la práctica de la traducción. Pero poco a poco el "roman" dejó de ser una simple traducción y se convirtió en la novela, que se planteaba como un nuevo tipo de expresión, distinto de la épica no sólo en su forma, sino también en su contenido e intención, y dirigido a la nobleza, estamento que había ido evolucionando en sus estructuras y costumbres, que se verán reflejadas en esta manifestación literaria. Sin embargo, los primeros "romans" franceses, escritos a mediados del siglo XII en octosílabos pareados y destinados ya no al canto, como la épica, sino a la lectura, son adaptaciones de obras de la Antigüedad clásica. Se trata de los "romans antiques": Roman d'Alexandre, del que se conocen tres versiones redactadas entre 1130 y 1190 (dos de ellas realizadas por Albéric de Pisançon y Alexandre de Paris), Roman de Thèbes (ca. 1150), Roman d'Enéas (ca. 1160) y Roman de Troie (ca. 1165), de Benoît de Sainte-Maure.

Así, en sus inicios, la novela se limitó a la traducción o adaptación y su principal ambición era contar una "verdad histórica" en la que se hablara del origen legendario de la corte a la que pertenecían sus autores. En efecto, todos ellos retomaron en sus obras una antigua leyenda según la cual, tras la caída de su ciudad, los troyanos huyeron a Italia, Francia, España e Inglaterra, donde fundaron las principales dinastías europeas. Sin embargo, los "romans antiques" no dejan de ser traducciones muy libres en las que observamos importantes innovaciones con relación a los modelos utilizados. Dichos relatos fueron adaptados de manera anacrónica a la sociedad del siglo XII: se redujo considerablemente el aspecto mitológico y se introdujeron elementos maravillosos ajenos a la Antigüedad. Pero sobre todo, se le dio 
un lugar importante al tema del amor, anunciando así el advenimiento de la novela artúrica, donde el amor cortés, bajo la influencia de la poesía lírica, alcanzará su pleno desarrollo, definiendo al género como una ficción de aventuras y amor.

La expresión "mettre en roman" fue poco a poco sustituida por "faire/ entreprendre un roman", que figura en el prólogo del Chevalier de la Charrette de Chrétien de Troyes, ${ }^{1}$ y en la que se hace énfasis ya no en la traducción, sino en la actividad creadora de un autor, poniéndose así de manifiesto la importante transformación del "roman" en novela. Fue con Chrétien de Troyes, cuya actividad literaria se sitúa entre los años 11641190 , cuando el "roman" incursionó definitivamente en el ámbito de la ficción. La leyenda artúrica se convirtió entonces en la materia de la creación novelesca, constituyendo un elemento fundamental no sólo en el nacimiento sino también en la evolución de la novela medieval francesa. Originaria de Inglaterra, la leyenda del rey Arturo se vio ampliamente desarrollada en la obra de Chrétien de Troyes, cuya influencia fue determinante en los escritores del siglo XIII. El objeto del presente estudio es definir brevemente las bases que permitieron el florecimiento de la novela artúrica francesa durante los siglos XII y XIII.

La leyenda artúrica penetró en la literatura francesa a través de la "materia de Bretaña", es decir, de los antiguos relatos celtas (galeses e irlandeses), que constituyeron una fuente inagotable de inspiración para los novelistas franceses. Fuente que les proporcionó no sólo el marco ideal para sus historias, la Gran Bretaña legendaria, sino también los héroes y un gran número de aventuras, motivos y elementos maravillosos de la mitología celta, que fueron adaptados a la ideología cortés y caballeresca exaltada en la novela artúrica. Pero la principal fuente de los escritores fue sin duda alguna la Historia Regum Britanniae, crónica redactada hacia 1138 por el clérigo galés Geoffrey de Monmouth, que abarca un periodo bastante largo, desde el reinado de Bruto, bisnieto de Eneas (siglo XII a. C.) hasta el de Cadvaladro (siglo VII d. C.). Geoffrey dedica una parte importante de su historia al relato de las aventuras y proezas de Arturo, guerrero del que hablaban las narraciones de tradición oral y que el autor convierte en un gran rey. Su crónica fue recibida con entusiasmo por Enrique II de Plantagenêt y Leonor de Aquitania, dueños del trono inglés y de parte del territorio francés, quienes

\footnotetext{
${ }^{1}$ Des que ma dame de Chanpaigne

Vialt que romans a feire anpraigne

Je l'anprendrai mout volentiers

(Le Chevalier de la Charrette, ed. A. Foulet 1989: vv. 1-3.)
} 
vieron en el personaje de Arturo a un digno representante de la dinastía Plantagenêt. La Historia Regum Britanniae fue conocida en Francia gracias a la traducción realizada por Robert Wace en 1155, el Roman de Brut. A partir de ella, los escritores de la época, apoyados por Leonor y Enrique II, se encargaron de dar forma al mito artúrico.

Con Chrétien de Troyes, quien trabajó al servicio de María de Champaña, hija de Leonor de Aquitania, la "materia de Bretaña" sustituyó definitivamente a la materia antigua y se impuso en el gusto de la nobleza. En su obra cristalizaron, a través del mito artúrico, los valores de un nuevo ideal de sociedad elaborado en la corte de los Plantagenêt, la cortesía, síntesis, como lo señala Reto R. Bezzola, "de la chevalerie guerrière du Nord, de l'amour courtois du Midi et de la tradition cléricale du prince et du gentilhomme cultivé" (1963). En estos valores se verán reflejadas las más altas aspiraciones de la nobleza. Chrétien conoció posiblemente algunos relatos bretones de transmisión oral que le proporcionaron ciertos temas y motivos narrativos. Pero se inspiró fundamentalmente en el Roman de Brut de Wace, y específicamente en la parte dedicada al reinado de Arturo, de donde retomó a los héroes que figurarian en sus novelas: Arturo, Ginebra, su esposa, y los caballeros del rey, miembros de la Mesa Redonda. A partir de esta materia, el autor planteó una nueva forma de estructurar el espacio y el tiempo del relato, distinta de la de los "romans antiques" y el Roman de Brut, concebidos como crónicas.

A diferencia del Roman de Brut, donde Arturo es presentado como un gran conquistador, las novelas de Chrétien muestran la figura estática de un rey cuya función primordial es presidir su corte, velar por la unidad de los caballeros de la Mesa Redonda y por el respeto de las costumbres ${ }^{2}$ que permiten al héroe, al caballero, salir del espacio cerrado de la corte en busca de aventuras. En un pasaje de Erec et Enide, Arturo declara que, como

${ }^{2}$ Mientras que la misión de los caballeros de la Mesa Redonda es garantizar el poder y la supremacía del reino, la de Arturo es retener en su corte a esta elite y asegurar así su cohesión. Aunque el rey no es el héroe de ninguna novela, no deja de ser una figura central, pues es el garante de los valores corteses y caballerescos de esta sociedad; es el encargado de velar por el respeto de sus usos y costumbres, de la ley, la justicia y la paz. En otras palabras, la virtud monárquica por excelencia, encarnada en el personaje de Arturo, es la aceptación de un tradicionalismo feudal, de un orden establecido e inamovible. El poder del reino reposa en esta relación armónica que el rey establece con sus caballeros, en esta repartición ideal de funciones, que Dominique Boutet resume así: "au roi la fonction de justice et l'obligation de largesse, aux vassaux la fidélité et la tâche de maintenir, voire d'étendre l'ordre arthurien, la paix arthurienne, dont le roi n'est que le garant moral (1979: 94). 
rey, debe vigilar que se respeten las costumbres establecidas por sus ancestros. Y una de ellas, la más importante, es dejar que la aventura penetre en la corte, perturbando el orden, y permitir que el caballero elegido parta en su búsqueda, la lleve a buen fin y restablezca así el orden perdido. De esta forma, las novelas de Chrétien reproducen el mismo esquema inicial: reunión en la corte un día de fiesta, irrupción de una aventura y salida del caballero elegido. La realización de la aventura permitirá el regreso de la armonía en la corte, donde la irrupción de una nueva aventura desencadenará continuamente la acción.

Así, la aventura se impone como modelo de estructura narrativa de la novela artúrica y con ello se define un nuevo tipo de héroe, el caballero andante. Ya no se trata aquí del héroe épico de las epopeyas, encarnación de un linaje o un pueblo, sino de un caballero solitario en busca de aventuras que le permitirán probar sus capacidades y lo cubrirán de gloria. En un pasaje de otra novela de Chrétien de Troyes, el Chevalier au Lion, Calogrenant, respondiendo a la pregunta de un pastor, da una definición precisa del caballero andante:

Je sui, çou vois bien, uns chevaliers

Qui quier [...]

Aventures, pour esprouver

Ma proeche et mon hardement

(ed. D. F. Hult: 722-723)

[Soy, como lo puedes ver, un caballero

y busco $[\ldots]$

aventuras para poner a prueba

mi valor y mi coraje]

A partir de Chrétien de Troyes el término chevalier errant designará a este tipo de héroe. Entre bosques y castillos, el caballero se topa constantemente con la aventura, que consiste en luchar contra todo tipo de hostilidad que impide la armonía y la paz: caballeros desafiantes, malas costumbres impuestas en algún castillo o seres maravillosos. La aventura, a través de la cual el héroe se consagra al ser reconocido por la comunidad como un gran libertador, es ante todo signo de elección, pues sólo la encuentra el que es digno de ella. Esta idea alcanzará sus verdaderas dimensiones en la búsqueda del Grial.

Las grandes hazañas del héroe le darán un lugar privilegiado dentro de la sociedad caballeresca, permitiéndole así conquistar a la dama de la que está enamorado. Sus proezas son siempre motivadas por este amor: el de Lanzarote por la reina Ginebra, en Le Chevalier de la Charrette, el de Yvain 
por Laudine, en Le Chevalier au Lion, o el de Erec por Enide, en Erec et Enide. La estrecha relación entre proeza y amor constituye la base esencial de la novela. Se trata de una relación recíproca: el caballero realiza asombrosas hazañas motivado por el amor y es a su vez amado por sus grandes proezas. El amor se convierte, en un personaje como Lanzarote, en principio de virtud caballeresca. Son las proezas que va acumulando en nombre de su dama lo que lo convertirán en el mejor caballero del mundo y lo harán finalmente digno de ser amado. Así, desde las primeras obras de Chrétien de Troyes, el amor, en su estrecha relación con la proeza, será un elemento fundamental de este género literario.

Chrétien de Troyes marca de manera decisiva la historia de la novela medieval. Gran parte de la producción posterior atestigua la influencia de este escritor que dejó establecidos los elementos constitutivos del género tanto a nivel formal como temático. Elementos que permitirían la creación de los grandes ciclos artúricos en prosa realizados durante el siglo XIII. Los autores posteriores retomaron de Chrétien el marco espacio-temporal artúrico en el que se desarrolla la ficción, los personajes pertenecientes a este universo, así como el modelo de estructura narrativa basado en la aventura. Este tipo de estructura, que implicaba el regreso periódico al mismo espacio y tiempo (la corte del rey Arturo, un día de fiesta ), abría las posibilidades narrativas al infinito, pero también dejaba la historia artúrica inconclusa, suspendida en un momento preciso, que Chrétien había tratado de dilatar al máximo multiplicando las aventuras. Los novelistas vieron entonces la necesidad de inventar el pasado y el futuro de este universo, de relatar el origen y destino de sus héroes. La idea cíclica fue adoptada y los escritores del siglo XIII se encargaron de reescribir, desarrollar y completar los temas y motivos legados por Chrétien de Troyes. De esta manera, mediante el proceso de reescritura, se fue configurando la historia completa del universo artúrico.

La adopción de la forma cíclica permitió importantes transformaciones en el género. Transformaciones que estuvieron estrechamente vinculadas al desarrollo de un tema específico, el del Grial, objeto maravilloso introducido por primera vez en el universo artúrico en el Conte $d u$ Graal de Chrétien de Troyes. El misterio de dicho objeto había quedado sin resolver en esta novela inconclusa, dejando abiertas las posibilidades a los autores de las cuatro Continuaciones del Conte du Graal, realizadas durante las primeras décadas del siglo XIII.

Sin embargo, no fueron estas obras, sino la trilogía atribuida a Robert de Boron y redactada a principios del siglo XIII, la que trazó por primera vez la historia completa del Grial, ligándola a la del rey Arturo y los caballeros de la Mesa Redonda. Esta primera recopilación cíclica, formada por la Estoire 
del Saint Graal, el Merlin y el Perceval, relata el origen del Grial en la época bíblica (el objeto es identificado como el Cáliz de la Última Cena y en el que José de Arimatea recogió la sangre de Cristo después de su crucifixión), su búsqueda en los tiempos de Arturo y la desaparición del universo artúrico. A partir de Robert de Boron, la búsqueda de la Santa Reliquia y el descubrimiento de los misterios divinos encerrados en ella se convertirán en la suprema aventura para la cual fue instituida la orden de los caballeros de la Mesa Redonda. Pero ya no se trata aquí de una aventura mundana, sino de una aventura espiritual.

Al identificar el Grial como el Cáliz de la Última Cena y en el que José de Arimatea recogió la sangre de Cristo, la pretensión de los autores era ligar la historia artúrica a la Historia Santa y darle así cierta dimensión de "verdad". Ésta fue quizás una de las razones que los empujó a adoptar la prosa, utilizada ya en el siglo XIII en la escritura de la historia. Por otra parte, gracias a la prosa, menos limitante que el verso, se pudieron desarrollar nuevas técnicas narrativas, necesarias para la redacción de ciclos. Técnicas que permitieron crear, dentro de la ficción, la ilusión de un tiempo real que transcurre y se dirige hacia un final.

La trilogía de Robert de Boron, cuyo marcado tono religioso la distingue de las novelas de Chrétien de Troyes, en las que el amor cortés ocupa un lugar preponderante, marca la primera etapa en la evolución de los ciclos artúricos en prosa. Sin embargo, no fue en esta obra sino el Lancelot-Graal o ciclo de la Vulgate (1215-1230), donde quedó definitivamente configurada la historia del Grial. Este vasto conjunto anónimo consta de cinco partes: la Estoire del Saint Graal, el Merlin (obras de Robert de Boron), una continuación del Merlin denominada Suite-Vulgate, el Lancelot en prose, la Queste del Saint Graal y la Mort le Roi Artu. En este gran ciclo se incluyó y se completó toda la materia artúrica existente. Así, por ejemplo, en el Lancelot en prose, novela en la que se manifiesta claramente el espíritu cortés, se retomó de Chrétien de Troyes el tema del amor adúltero entre Lanzarote y Ginebra; en la Queste del Saint Graal, obra profundamente religiosa, se retomó el tema de la búsqueda del Grial planteado por Chrétien y Robert de Boron; la última parte del conjunto, la Mort le roi Artu, relata la muerte de Arturo a manos de Mordred, inspirándose en Robert de Boron y en la crónica de Wace.

El Lancelot-Graal fue concebido bajo un doble espíritu: cortés y religioso. El amor cortés, tan exaltado en el Lancelot en prose a través de la figura de Lanzarote, el fin'amant por excelencia, se convierte en un terrible pecado de lujuria en la Queste del Saint Graal, donde se condenan todos los valores profanos de la ideología caballeresca. Valores que se vuelven un 
verdadero impedimento para todo aquel que quiera participar en la búsqueda del Grial, pues ya no se trata aquí de una aventura mundana como todas las demás, sino espiritual, destinada ya no a un caballero valiente y cortés, como Lanzarote, sino casto y puro como Galaad. Así, en la Queste, la historia artúrica adquiere un marcado tono religioso y asistimos al nacimiento de un nuevo tipo de héroe, el caballero al servicio de Dios, creado a imagen de los Templarios. Los nuevos valores de esta caballería celestial, como la llama el autor de la Queste, son la castidad, la humildad, la penitencia y la renuncia a toda gloria mundana. Desde el inicio de la novela, la búsqueda del Grial se define como la suprema aventura destinada al elegido divino, Galaad, quien gracias a su pureza de cuerpo y alma logrará acceder a la mística contemplación de la Santa Reliquia.

La dimensión religiosa de la Queste es indiscutible. Su autor condena los defectos de la caballería terrenal, y el adulterio de Lanzarote y Ginebra es aquí la causa del fracaso de este héroe en la búsqueda del Grial. Sin embargo, el mismo autor no pudo concebir el nacimiento de la nueva caballería celestial más que en el seno de la caballería profana que, dominada por el espíritu cortés, alcanza la excelencia en Lanzarote, padre de Galaad.

La manifestación de este doble espíritu, cortés y religioso, constituye pues la base del ciclo Lancelot-Graal. Y fue sin duda alguna en la literatura del Grial donde se reflejaron los más altos ideales de la clase feudal, encarnados en la figura de Galaad.

Como ya lo señalamos, en los ciclos se relató el origen, la trayectoria y el destino de los principales personajes del universo artúrico. Así, por ejemplo, en el Merlin de Robert de Boron se narra el nacimiento de Arturo y el texto concluye con su coronación, mientras que el origen de otros personajes como Gauvain, Yvain, Mordred, Lanzarote, etcétera, es relatado en el ciclo Lancelot-Graal. En cuanto al destino de dichos héroes, tras su amplia trayectoria trazada a lo largo del ciclo, el fin de la última aventura, la del Grial, marca también el fin de esta caballería artúrica, cuya razón de existir era justamente la aventura. Condenados a la inacción y dirigidos por un rey que poco a poco empieza a perder su poder y a mostrar sus deficiencias, la caballería de la Mesa Redonda entra en una fase de decadencia en la que, tras su gloriosa consagración en la aventura del Grial, manifiesta la imposibilidad de mantener viva la utopía del amor cortés.

En efecto, el descubrimiento, en la Mort Artu, del adulterio entre Lanzarote y Ginebra es el detonador de la crisis que debilitará al reino, que será finalmente destruido por Mordred. A través de esta tragedia se refleja, como lo señala Jean Frappier en su estudio de la Mort Artu, el fracaso del ideal cortés frente a un viejo orden feudal dominado por un exagerado sentido del 
honor que provocará conflictos entre los diferentes clanes de la Mesa Redonda. Traiciones, venganzas, desmesura y violencia serán los principales factores de desequilibrio de una caballería que finalmente muestra la insuficiencia de los valores en los que estaba sustentada.

Después del Lancelot-Graal, la historia artúrica continuó desarrollándose. Los escritores la vincularon a la historia de Tristán, inspirándose en las novelas del siglo XII de Béroul y Thomas, y redactaron el ciclo del Tristan en prose, del que se conocen cuatro versiones principales, elaboradas entre el siglo XIII y principios del XIV (Baumgartner 1975). En este conjunto se observa también una fuerte influencia del Lancelot-Graal así como del ciclo denominado Post-Vulgate. Los autores del Tristan en prose retomaron de estas obras un gran número de aventuras ajenas a la leyenda tristaniana. Así, la historia de Tristán, quien se convertirá aquí en caballero de la Mesa Redonda y en uno de los buscadores del Grial, será totalmente integrada al universo artúrico. El héroe se vuelve una especie de doble de Lanzarote, y su relación con la reina Iseo es equiparable a la de Lanzarote y Ginebra.

Entre las aportaciones importantes de este nuevo ciclo cabe señalar la introducción de poemas líricos, los lais arthuriens, redactados por los mismos personajes, que cantan las dichas y sufrimientos del amor. Muchos de ellos son compuestos por el mismo Tristán, quien no sólo es un caballero ejemplar, sino también un hombre cultivado, poeta y músico. La otra gran innovación que se observa en este ciclo es la modificación que sufre la imagen del caballero a través de la figura de Dinadan, en la que se cuestionarán los más altos valores de la caballería artúrica. Adversario y crítico de esta ideología, el personaje declara abiertamente que prefiere renunciar a todo honor y toda gloria si esto implica poner en peligro su vida. Tampoco está dispuesto a sufrir por un amor ni a realizar proezas en nombre de su dama, pues nada justifica sacrificar la tranquilidad, la buena vida y la seguridad. En otras palabras, Dinadan no le encuentra ningún sentido al exagerado honor y al valor del caballero, ni tampoco a las exigencias del amor cortés. A una pregunta similar a la que el pastor le hace a Calogrenant en Le Chevalier au Lion, Dinadan responde lo siguiente: "je suis un chevalier errans qui chascun jor voiz aventures querant et le sens du monde: mais point n'en puis trouver" ["soy un caballero andante que cada día va en busca de aventuras que le den sentido a este mundo: pero no lo puedo encontrar"]. Así, la aventura, como posibilidad de dar un sentido a la existencia del caballero, se convierte en un esfuerzo inútil en el personaje de Dinadan.

El proceso de reescritura de la historia artúrica dio también lugar a la redacción de otro conjunto más que ya hemos mencionado, el ciclo PostVulgate, realizado hacia 1240 y del que únicamente se conserva la novela 
conocida como Suite du Merlin, que es una continuación del Merlin de Robert de Boron distinta de la perteneciente al Lancelot-Graal. Se cree que el ciclo estaba formado originalmente por la Estoire del Saint Graal, el Merlin, la Suite du Merlin y una Queste-Mort Artu, versión Post-Vulgate. De estas dos últimas novelas, la Queste y la Mort Artu, que son una refundición de las del Lancelot-Graal, sólo se conservan algunos fragmentos franceses y dos adaptaciones extranjeras, una española, La Demanda del Sancto Grial, y otra portuguesa, La Demanda do Santo Graal. $^{3}$

Retomar, completar, reinterpretar, contar nuevamente y de otra manera la historia artúrica fue el objetivo de los autores de este nuevo ciclo, quienes desarrollaron ampliamente los temas tratados por sus predecesores, llenando las lagunas, relatando lo que aún no se había dicho, con el fin de ofrecer una historia más completa. Inspirándose en el Lancelot-Graal y en la primera redacción del Tristan en prose, novelas con las que se establecieron sólidos vínculos, el autor o los autores del ciclo Post-Vulgate trataron de dar una explicación definitiva de los principales acontecimientos artúricos (el desencadenamiento de las aventuras maravillosas del Grial, la devastación de la tierra y la destrucción del reino de Logres). Como los escritores anteriores, los responsables de este nuevo ciclo no inventaron nuevos temas, sólo desarrollaron ampliamente el legado de la tradición artúrica y le dieron un nuevo sentido. Así, en el ciclo Post-Vulgate se observa un tono fatalista muy marcado y una orientación moral que ya no tiene nada que ver con el espíritu cortés del Lancelot en prose, ni tampoco con el misticismo de la Queste. El espíritu pesimista característico de este nuevo ciclo se observa claramente en la Suite du Merlin a través de dos temas fundamentales, el pecado y la mescheance (mala fortuna), que marcarán todos los trágicos acontecimientos de la historia artúrica y en los que se refleja una desmitificación de los valores de la imagen ideal de la caballería.

A manera de conclusión podemos decir que fue precisamente en la época que marca el advenimiento de una literatura escrita en francés cuando asistimos al nacimiento de la novela, que se irá definiendo poco a poco como un gran género. Si en sus inicios el "roman" se presenta como una adaptación de textos de la Antigüedad, en muy poco tiempo los autores inventarán sus propios relatos de ficción. Desde Chrétien de Troyes hasta el ciclo Post-Vulgate el género se fue configurando y enriqueciendo a través del proceso continuo de reescritura. A lo largo de su desarrollo, sufrió importantes transformaciones, ligadas a los nuevos valores e ideales que se

${ }^{3}$ Cf. la edición de la Version Post-Vulgate de la "Queste del Saint Graal" y de la "Mort Artu", realizada por Fanni Bogdanow: 1991, t. I., introd. 
fueron planteando. La gran madurez que alcanzó la novela artúrica se refleja, sin duda alguna, en la enorme reputación que adquirió en toda Europa. No hay que olvidar que, en ciertos países europeos, las primeras novelas escritas en lengua vulgar fueron adaptaciones de modelos franceses. A través del legendario universo artúrico, los novelistas franceses inventaron una forma de heroísmo y de expresión literaria que se impuso en Europa durante varios siglos.

\section{Obras citadas}

Baumgartner, Emmanuèle. 1975. Le "Tristan en prose". Essai d'interprétation d'un roman médiéval. Ginebra: Droz.

Bezzola, Reto R. 1963. Les origines et la formation de la littérature courtoise en Occident. París: Champion.

Boutet, Dominique y Armand Strubel. 1979. Littérature, politique et société dans la France du Moyen Age. París: Presses Universitaires de France.

Chrétien de Troyes. 1989. Le Chevalier de la Charrette, ed. de Alfred Foulet y Karl D. Uitti. París: Bordas.

1994. Le Chevalier au Lion, ed. de David F. Hult, en Chrétien de Troyes. Romans. París: Le Livre de Poche.

Frappier, Jean. 1936. Etude sur la "Mort le Roi Artu", roman du XIII siècle. 3a. ed. Ginebra: Groz, 1972.

Version Post-Vulgate de la "Queste del Saint Graal" et de la "Mort Artu", ed. de Fanni Bogdanow. 1991. París: Société des Anciens Textes Français. 3 vols. 